\title{
Health Insurance in Latvia - Public Services and Private Undertakings
}

\author{
Jelena Alfejeva \\ Law Faculty, Economic and Culture University, Riga, Latvia
}

Email address:

alfejeva $a$ inbox.lv

\section{To cite this article:}

Jelena Alfejeva. Health Insurance in Latvia - Public Services and Private Undertakings. International Journal of Sustainable Development Research. Vol. 5, No. 4, 2019, pp. 106-111. doi: 10.11648/j.ijsdr.20190504.13

Received: April 26, 2019; Accepted: May 27, 2019; Published: December 25, 2019

\begin{abstract}
The provisions of the law of the Latvian Republic related to health care are not on basis on competition law, offering it as public services only. On the other hand, health insurance provided by private insurance undertakings covers significant part of health care services and mostly used by state entities and municipalities. The private health insurance ensures also a significant part of medical expenses for individuals. At the same time, the European Union regime for the nonlife insurance including health insurance (in a number of directives and regulations) limits the ability of Member States of the European Union to intervene in insurance conditions and prices, except for schemes of a social security. These conditions reflects the necessity of compliance between compulsory insurance coverage in the health insurance if it has been created (Latvia still has no it) and bringing of the risk to private insurance undertakings that characterizes the increasing importance of health insurance the Latvian Republic as part of the policy mix. There is also opportunity for Latvia to apply some mentioned policy mix to problems of funding and guaranteeing the provision of health care. However, it is still difficult to find the necessary balance for two mentioned parts of the main process.
\end{abstract}

Keywords: Health Insurance, Competition Law, State Aid

\section{Introduction}

The aim of the research is to clarify how health insurance on competition basis can be used ensuring health care.

The research hypothesis states that health insurance on a competition basis can be used to improve access to health care.

General scientific methods as well as special legal research methods - analysis and synthesis methods, comparative method and historical method were used. The research was based on the analysis of documents, decisions of the Court of Justice of the European Union (EU), legal acts, as well as personal observations.

Considering that primarily in the EU health care systems are a phenomenon of the Bismarck system over the past 20 years from Independence, the Latvian State tried to prove that state healthcare is a more preferable parallel developing duplicate of state healthcare package offering by voluntary health insurance.

Usually health care is ensured by public sector with a basic level of health care and some voluntary supplementary insurance. In all cases health insurance involves third party payment of medical expenses as well as a pooling of risks, in some cases based on solidarity within the population of the particular insurer, and sometimes between insurers if a system of risk equalisation is implemented [1].

It is fair to say that the current health care situation in Latvia does not match the standard level of healthcare in the EU research mentioned.

This paper will examine EU law rules that apply to private undertakings. By providing health insurance as well as main features of situation on Latvia making light analysis about the potential usage of private health insurers in the healthcare system.

Finally, some general conclusions will be drawn on the criteria applied. The research concludes that the usage of private insurance undertakings in the healthcare organization under state rules can improve the quality of services and reduce costs based on competition. 


\section{Healthcare Systems Organization}

There is possible historically to speak about two healthcare systems organization models- the Beveridge model and the Bismarck model.

The Beveridge model is a state healthcare as public services, but the Bismarck model is operating with risk equalisation and allows involving private undertakings. Both models had some problems in practical realization also historically and more and more problems arose in the process of modernization during development.

From the beginning, both systems were applied as healthcare organization systems recognizing the state obligation to ensure the main level of healthcare for its citizens. Developing state functions in healthcare organization as the financial systems could be divided to two main group related to the financing from state budget, which founded from taxes, and the direct financing through health insurance using or not private undertakings. Private insurance undertakings also can be used alternatively to state social insurance or independently.

The Bismarck system is based primarily on social insurance contributions, but the financing of the Beveridge system is from taxes [2-3]. Therefore, a general classification into two basic systems is still possible but is not so actual. Many researchers now stay that Beveridge vs Bismarck health care systems are important for review only historically, but no longer conceptually relevant because sources are not systems.

As follows from the development of health care systems in European countries over time, the Bismarck model is in use as more preferable.

But the main question for stating of each country healthcare system - how private undertakings can be used. The state contribution will depend from a level of using private insurance undertakings. This question makes it necessary to determine the possibility of regulating the activities of private insurance organizations in the required manner.

The scope of the Solvency II Directive define the status of commercial health insurance related to public statement with regard to the insured risks so far so it is necessarily for the objective of protecting the general good. The Article 85 of it stays that the objective may also be achieved by requiring undertakings offering private health cover or health cover taken out on a voluntary basis to offer standard policies in line with the cover provided by statutory social security schemes at a premium rate at or below a prescribed maximum and to participate in loss compensation schemes.

Therefore, it stays that private health insurance is an alternative to social security. The private schemes of health insurance may be subject to general good conditions and prior public scrutiny as well as these conditions concern mainly the actuarial nature on which the scheme is based as well as (inter alia) the right to carry over benefits to other providers [1].
Analysing the structure of healthcare financing in the Organisation for Economic Cooperation and Development (OECD) countries the main finding was that every of it focused on the mixed public and private financing in this area [4-8].

So possible preferable organization of healthcare is on basis of symbiosis of public and private elements and for improvement of existing situation additional analysis is necessary.

\section{Choice Between Private Insurance Undertakings and Public Services in EU}

Healthcare financing issues cannot be resolved simply. There are a lot of indications which are usable for evaluations. There is not clear understanding of the main way of resolving the problems - not among the scientists, not also practisers.

Private healthcare schemes incur problems with poor cover, whereas financing based on general taxes tends to force people to similar standards without considering individual demand or willingness to pay (Barros 2007). The public financing sources also are the subject of causing excessive spending due to moral hazard and bureaucratic budget maximizing strategies [9]. There is a point of view that public financing can promote state capacity to control spending [10] which seems need to evaluate critically in the context of mentioned bureaucratic features of state activities.

Public schemes have been considered preferable to private financing in terms of guaranteeing financial stability without compromising access to healthcare and equity concerns [11]. Despite of this point of view the situation in Latvia proves that it can be dangerous and far from financial stability if the level of covering necessary healthcare services by state is not adequate (poor).

However, the public sources of financing can be partitioned into the direct taxes and social insurance. These public financing streams involve distinct characteristics concerning risk pooling and different effects on generosity, equity, coverage, or sustainability [12].

A state health care as public services (the Beveridge model) has two main problems: for the first, it has difficulties to provide care for any reasonable costs, for the second it cannot avoid the dangers of poor quality. Health insurance system using private undertakings (the Bismarck model) can achieve high quality but also has problem to ensure care for all at an affordable cost. The best chance of achieving a reliable financial base for health services is to use a combination of both these approaches.

The private compulsory health insurance system on basis of private insurance undertakings would be promoting competition rules in the industry itself, which would allow existing financing to be used more effectively. Consequently, state-regulated competition would improve the system as a whole. 
The classification of healthcare in Latvia until 2018 suggests using the Beveridge model with financing from the main state budget. Starting from the beginning of 2018 the model is not significantly changes but new system uses "insurance" in its name and financing is organized from state special social budget.

The private insurance undertakings have no any opportunity for participating in the main healthcare system, despite the fact that private health insurance in Latvia is widely distributed and the vast majority of state institutions use it for paying for healthcare services for their employees. The best private health insurance also is typically available through the employer and thus the available services depend on the deal each particular employer has made with the insurance company of their choice. There is almost impossible in Latvia to buy health insurance for individual because of information asymmetry and bad choice.

In turn, raising taxes to finance a healthcare system only ruins the system as a whole since taxes are already high.

A private compulsory health insurance system would mean that the working population purchases an insurance policy from a private insurance company, which concludes contracts with the medical institution for the provision of services. The state, on the other hand, covers groups such as children, pensioners, poor people and the like.

As it was mentioned before, activities of private undertakings in social health insurance can be strictly subject of state regulation.

It would be necessary for avoiding of negative feathers of using of private health insurers in state organization of healthcare.

\section{Competition Law and Health Insurance}

The EU law provides a unified regulatory framework for competition law including state aid. The regulation of the insurance sector through directives in the EU is consistently subject to strict guidelines that limit the ability of Member States to intervene in insurance conditions. The Directive Solvency II for non-life insurance (and previous versions of Directive in non-life insurance) state an exception from this rule for schemes that substitute for social security.

The compulsory coverage and risk-privatization balancing act reflects in the growing importance of health insurance in the political systems of Member States apply to financing problems and guarantees the delivery of healthcare.

Health care in the EU states is based on insurance in manner of the Bismarck system of which it forms the defining feature. Usually state health insurance covers minimum necessary packages of care and other part is covered by supplementary (voluntary) insurance [8].

In any case, health insurance includes payments for medical expenses by third parties, as well as aggregation of risks, in some cases, based on solidarity among clients of a particular insurer, and sometimes between insurers, if a risk equalization system is in use [1].

The EU law on state aid derives from the Treaty on the Functioning of the European Union (TFEU) and aims to prevent member states from unfairly distorting competition within the EU, except in certain permitted circumstances. Where a state intervention distorts competition, this will usually constitute state aid. TFEU expressly prohibits the granting of state aid except in certain circumstances where the European Commission has discretion to approve state aid that does not unacceptably distort the internal market.

Competition and state aid rules apply only to commercial activities. This is in line with its objective of completing the internal market freedoms that apply to the authorities in the Member States in removing barriers to trade expressed by the former, with which private competition rivals resurrect.

The European Court of Justice held in 1991 in Case C41/90 Höfner and Elser v Macrotron GmbH [12] in the context of executive job recruitment services, that a public body could be subject to competition laws. Furthermore, by failing to satisfy demand for a good or service, the exclusive right of the German government to regulate employment services could amount to the abuse of a dominant position.

In this context it was held immaterial whether there had been a public monopoly at a given time as such services were elsewhere and at other times performed competitively.

The European Court of Justice also defined an economic activity in the 2001 Pavel Pavlov and Others v Stichting Pensioenfonds Medische Specialisten in joined cases C180/98 to C-184/98 (concerning supplementary pension schemes for medical specialists) as "any activity consisting in offering goods and services on a given market" [14].

This concept was discussed by researchers widely [15].

So summarising the main general insurance cases relevant to the concept of undertaking under EU law the finding is that the solidarity concept is associated less with not-profit activities than with standardised benefits independent from the amount of contributions paid. This contradicts with undertakings providing benefits based on capitalisation. [1]

The interesting case (Case T-216/15) in the context of undertaking and EU competition law was the case Dôvera zdravotná poist'ovňa et al $\mathrm{v}$ European Commission. On 5 February 2018, the General Court annulled Commission decision 2015/248 concerning health insurance in Slovakia [16].

The Commission in annulled decision of 2015 had concluded that the providers of health insurance in Slovakia were not undertakings even though two of them were private companies. A number of public and private health insurers provided coverage for compulsory health insurance to Slovak residents. There is in Slovakia also a risk-sharing scheme for risk and, consequently, medical expenses sharing between all insurers.

One insurer claimed that another benefited from State aid. The Commission, however, considered, that public funding did not constitute State aid because the compulsory health insurance, as organised and carried out in Slovakia, was not an economic activity and, therefore, health insurers in 
Slovakia could not be classified as an undertaking.

Therefore, the General Court determined that health insurance is an economic activity. This conclusion was made on basis of the main principles of the EU law. Article 107(1) of TFEU applies to the activities of undertakings. In the context of EU competition law, any entity engaging in an economic activity, regardless of its legal status and the way in which it is financed, is an undertaking.

The General Court found that certain bodies entrusted with the management of statutory health insurance and old-age insurance schemes pursued an exclusively social objective and did not engage in economic activity, for example in the case of sickness funds which merely applied the law and could not influence the amount of the contributions, the use of assets and the fixing of the level of benefits. Their activity, based on the principle of national solidarity, was entirely non-profit-making and the benefits paid were statutory benefits bearing no relation to the amount of the contributions.

However, the Court has held that non-profit-making organisations, contributing to the management of the social security system and subject to the solidarity principle, could be considered to be carrying out an economic activity. It is therefore clear from the case-law that the social aim of a health insurance scheme is not in itself sufficient to exclude classification as an economic activity. It must also be examined whether that scheme can be regarded as applying the principle of solidarity and is subject to the supervision of the State which established it. Those factors are liable to preclude a given activity from being regarded as economic.

In view of the fact that the law allows health insurance companies, first, to make, use and distribute profits and, second, to compete to a certain degree in terms of quality and services offered it is impossible to note that its activities are not economic.

Indeed, as the European Commission rightly states that the ability to use and distribute profits is regulated more strictly than in normal commercial sectors, since that power is, in the present case, subject to the fulfilment of requirements intended to ensure the continuity of the scheme and the attainment of the social and solidarity objectives underpinning it. However, that becomes irrelevant for the purposes of excluding the economic nature of the activity, once the market operators in question seek to make a profit. In any event, the fact that Slovak health insurance companies are freely able to seek and make a profit shows that, regardless of the performance of their public health insurance task and of State supervision, they are pursuing financial gains and, consequently, their activities in the sector fall within the economic sphere. Therefore, the strict conditions framing the subsequent use and distribution of profits which may result from those activities does not call into question the economic nature of such activities.

So ensuring healthcare as health insurance it is normally possible to use health insurers - private undertakings.

\section{Possible Benefits of Competition in Healthcare}

The main benefits of competition is improving of performance and innovation. It benefits individuals by enabling to choose from an array of good products at affordable prices. Competition also encourages the adoption of innovation as companies evolve and new ideas flourish in the marketplace.

While the benefits of competition is no longer contested, the role of competition in healthcare organizations is still the subject of active discussions which is much debated and researchers positions are often polarised [17].

Discussions about the role of competition in healthcare were described widely. Proponents of competition generally can be divided to two groups: the first is on basis of value of marketbased resource allocation and the second is on basis of possibility to correct the failures of government regulation. Both groups typically expect competition to strengthen patient choice, stimulate innovation, improve quality, enhance efficiency and control costs. Opponents of competition, in contrast, typically fear it will lead to undesirable outcomes such as a reduction in quality, access to health care based on ability to pay rather than medical need and, as a result, inequity and inefficiency in the distribution of health services $[18,19]$.

The right position that it is more valuable to think about the circumstances in which competition is more and less likely to be a good tool to achieve benefits, rather than whether or not it is "good" or "bad," per se [20].

Given these differing views, the European Commission asked its Expert Panel on Effective Ways of Investing in Health to consider if and how competition among health care providers might benefit health systems in the EU [21]. Summarizing the main findings and conclusions of the panel's final report it is possible to use forces and effects relating to competition as an instrument to achieve health policy goals but additional review is necessary.

In additional there was noted that the financial protection provided by health insurance, be it publicly provided or by private (commercial) health insurance, also plays an important role when patients choose a provider of health care. The level of protection and the rules of payment for within-network or out-of-network providers of care associated with health insurance coverage do matter introducing or increasing competition in the provision of health care services is a delicate policy exercise.

\section{Results}

The main findings of the study are:

1) Models of healthcare systems organization is two: the Beveridge model, which is a state healthcare as public services, and the Bismarck model, which is operating with risk equalisation and allows involving private undertakings. Both models historically transformed. Within the EU, the Bismarck system as the ground of healthcare is more preferable.

2) The Beveridge model can provide care for all at a 
reasonable cost but cannot avoid the dangers of poor quality. The Bismarck model on basis of insurance can achieve high quality but cannot ensure care for all at an affordable cost. The best chance of achieving a reliable financial base for health services is to use a combination of both these approaches.

3) For the purpose of the EU competition law, any entity engaged in an economic activity, that is an activity consisting in offering goods or services on a given market, regardless of its legal status and the way in which it is financed, is considered an undertaking. To qualify, no intention to earn profits is required, nor are public bodies by definition excluded.

4) Private health insurance may offer private health cover or the cover in line provided by statutory social security schemes and to participate in loss compensation schemes. And private health insurance also plays an important role when patients choose a provider of health care. Therefore, it stays that private health insurance is an alternative to social security.

5) It is possible to use forces and effects relating to competition as an instrument to achieve health policy goals ensuring additional review if necessary.

\section{Conclusion}

Previous analysis does not prepare for a comprehensive assessment of the possibility of using private health insurers in health care. This is not even an analysis of certain preconditions.

The obtained results allow concluding as the follows.

This article is written with the aim of pointing out the need to assess the possibility of incorporating private insurers into the provision of healthcare.

This is an extremely topical issue in Latvia, which has been properly addressed in light of the widespread use of voluntary health insurance, especially for public sector employees.

The current volume of literature on the structure of healthcare financing is primarily directed towards the public and private systems mixed.

Using of private insurance undertakings in healthcare organization under the state rules can improve quality of services and reduce costs based on competition. To reduce state financing, state rules need to ensure control and competition.

These conclusions can and should be used in the further reform of the healthcare system in Latvia.

\section{References}

[1] Sauter, W. (2011) Health Insurance and EU Law. TILEC Discussion Paper No. 2011-034; Tilburg Law School Research Paper No. 021/2011. [Accessed 28.02.2018]. Available from Internet: https://ssrn.com/abstract=1876304

[2] Kolmar, M. (2007), Beveridge versus Bismarck Publicpension Systems in Integrated Markets, Regional Science and Urban Economics 37, 649-169.
[3] Cremer, H. and P. Pestieau, (2003), Social Insurance Competition between Bismarck and Beveridge, Journal of Urban Barros, P. P. (2007), Editorial: The Slow and Unnoticed Changes in the Funding Mixed, Health Economics $16(5), 437-40$.

[4] Castles, F. G. (2004). The Future of the Welfare State: Crisis Myths and Crisis Realities. Oxford University Press on Demand, Economics 54, 181-196.

[5] Huber, M, and Orosz, E. (2003), Health Expenditure trends in OECD countries, 1990-2001, Health Care Financing Review, 21/2, 99-117.

[6] OECD (2011), Health at a Glance 2011: OECD Indicators, OECD Publishing. [Accessed 27.03.2018]. Available from Internet: http://dx.doi.org/10.1787/health_glance-2011-en

[7] Rothgang, H., Cacace, M., Frisina, L., Schmid, A. (2008). The Changing Public-Private Mix in OECD Healthcare Systems. 132-146.

[8] Götze, R., Schmid, A., (2012) Healthcare Financing in OECD Countries Beyond the Public-Private Split. Tran State Working Papers No. 160. [Accessed 28.02.2018]. Available from Internet: https://ssrn.com/abstract=1998037 or http://dx.doi.org/10.2139/ssrn.1998037

[9] Leu, R.E. (1986) Public and Private Health Services: Complementarities and Conflicts. In: Culyer, A.J. and Jonsson, B., Eds., Blackwell, Oxford, 41-63.

[10] Gerdtham, U. and Jonsson, B, (2000), International comparisons of health expenditure: Theory, data and econometric analysis, ch. 01, p. 11-53 in Culyer, A. J. and Newhouse, J. P. eds., Handbook of Health Economics, vol. 1, Elsevier, [Accessed 28.02.2018]. Available from Internet: https://EconPapers.repec.org/RePEc:eee:heachp:1-01

[11] Thomson, S, Foubister, T, Mossialos, E (2009), Financing health care in the European Union: challenges and policy responses. World Health Organization; 1 edition, 224.

[12] Wagstaff, A. (2010), Social health insurance reexamined. Health Economics, 19: 503-517.

[13] Judgment of the European Court of Justice (Sixth Chamber) of 23 April 1991, Klaus Höfner and Fritz Elser v Macrotron GmbH, Case C-41/90, European Court Reports 1991 I-01979, ECLI identifier: ECLI:EU:C:1991:161.

[14] Judgment of the European Court of Justice of 12 September 2000, Pavel Pavlov and Others v Stichting Pensioenfonds Medische Specialisten, joined cases C-180/98 to C-184/98, European Court Reports 2000 I-06451 ECLI identifier: ECLI:EU:C:2000:428.

[15] Nistor, L. (2011) Public Services and the European Union Healthcare, Health Insurance and Education Services Springer 1st Edition., XIV, 446.

[16] Judgment of the General Court of EU (Second Chamber), 5 February 2018, In Case T-216/15, ECLI:EU:T:2018:64.

[17] Schmidt, H. and Gostin, L O. and Emanuel, E. (2015), Public Health, Universal Health Coverage, and Sustainable Development Goals: Can They Coexist? The Lancet, Published Online June 30. [Accessed 28.02.2018]. Available from Internet: https://ssrn.com/abstract $=2625208$ or http://dx.doi.org/10.2139/ssrn.2625208 
[18] Barros, P. P., Brouwer, W. B. F., Thomson, S., \& Varkevisser, M. (2016). Competition among health care providers: helpful or harmful? The European Journal of Health Economics, 17, 229-233. http://doi.org/10.1007/s10198-015-0736-3)

[19] Goddard M. (2015) Competition in healthcare: good, bad or ugly? Int J Health Policy Manag.; 4 (9): 567-569. doi: 10.15171/ijhpm.2015.144
[20] Expert Panel on Effective Ways of Investing in Health (EXPH) (2015), provided by the European Commission Decision 2012/C 198/06, [Accessed 27.03.2018]. Available from Internet: https://ec.europa.eu/health/expert_panel/sites/expertpanel/files /008_competition_healthcare_providers_en.pdf 